\section{(A) Check for updates}

Cite this: Dalton Trans., 2019, 48, 9250

Received 29th April 2019, Accepted 25th May 2019 DOI: $10.1039 / c 9 d t 01789 e$ rsc.li/dalton

\title{
Crystal structure and stacking faults in the layered honeycomb, delafossite-type materials $\mathrm{Ag}_{3} \mathrm{Lilr}_{2} \mathrm{O}_{6}$ and $\mathrm{Ag}_{3} \mathrm{LiRu}_{2} \mathrm{O}_{6} \dagger$
}

\author{
Sebastian Bette, (DD *a Tomohiro Takayama, ${ }^{\text {a,b }}$ Viola Duppel, ${ }^{a}$ Agnieszka Poulain, ${ }^{c}$ \\ Hidenori Takagi (D) a,b and Robert E. Dinnebier (D)
}

\begin{abstract}
Powder samples of $\mathrm{Ag}_{3} \mathrm{Lil}_{2} \mathrm{O}_{6}$ and $\mathrm{Ag}_{3} \mathrm{LiRu}_{2} \mathrm{O}_{6}$ were synthesized from $\alpha-\mathrm{Li}_{2} \mid \mathrm{rO}_{3}$ and $\mathrm{Li}_{2} \mathrm{RuO}_{3}$ respectively by ion exchange in an $\mathrm{AgNO}_{3}$ melt. The crystal structures of the title compounds were solved from high resolution laboratory $\mathrm{X}$-ray powder diffraction (XRPD) patterns and from pair distribution function (PDF) analysis using synchrotron $\mathrm{X}$-ray powder diffraction data. In both crystal structures edge sharing $\mathrm{LiO}_{6 / 3^{-}}$ and $(\mathrm{Ir} / \mathrm{Ru}) \mathrm{O}_{6 / 3}$-octahedra form honeycomb like layers that are stacked in a staggered fashion. Silver cations, situated in-between the layers mediate the interlayer interactions by linear $\mathrm{O}-\mathrm{Ag}-\mathrm{O}$ bonds. Anisotropic peak broadening in the XRPD patterns and diffuse scattering occurring as streaks in the precession electron diffraction (PED) patterns indicate the presence of stacking faults, which could be also visualized by high resolution transmission electron microscopy (HRTEM). Possible alternative stacking sequences were derived from the ideal crystal and incorporated into a microstructure model. By applying a supercell approach that randomly generates and averages stacking sequences based on transition probabilities and combining it with a grid search algorithm, the microstructures, i.e. the degrees of faulting in the structures of the title compounds were refined to the measured XRPD data. In result the crystal structures of $\mathrm{Ag}_{3} \mathrm{Lilr}_{2} \mathrm{O}_{6}$ and $\mathrm{Ag}_{3} \mathrm{LiRu}_{2} \mathrm{O}_{6}$ were found to be vastly faulted with almost no coherence of the stacked layers.
\end{abstract}

\section{Introduction}

Iridium oxides as $\alpha^{-1}$ and $\beta-\mathrm{Li}_{2} \mathrm{IrO}_{3}{ }^{2,3}$ with a honeycomb like motif in their layered structure and related iridates, like $\mathrm{Na}_{2} \mathrm{IrO}_{3}{ }^{4,5}$ are currently attracting broad interest in the field of quantum magnetism and frustrated magnetism ${ }^{6}$ because of their possible relevance for the Kitaev quantum spin liquid state. $^{7}$ A honeycomb layer is built up from edge sharing $\mathrm{M}^{n+} \mathrm{O}_{6 / 2}{ }^{(6-n)-}$ octahedra forming condensed 6-fold rings. The charge balance is maintained by incorporation of cations like alkali metals or protons in the octahedral void in the centre of the 6-fold ring or into the interlayer space. The geometry of the interlayer voids depends on the stacking of the honeycomb

\footnotetext{
${ }^{a}$ Max Planck Institut for Solid State Research, Heisenbergstraße 1, 70569 Stuttgart, Germany.E-mail: S.Bette@fkf.mpg.de

${ }^{b}$ University of Stuttgart, Institute for functional Matter and Quantum Technologies, Pfaffenwaldring 57, 70569 Stuttgart, Germany

${ }^{c}$ European Synchrotron Radiation Facility (ESRF), 71 avenue des Martyrs, Grenoble, France

$\dagger$ Electronic supplementary information (ESI) available. CCDC 1912803 and 1912804. For ESI and crystallographic data in CIF or other electronic format see DOI: $10.1039 / \mathrm{c} 9 \mathrm{dt} 01789 \mathrm{e}$
}

layers. In $\alpha-\mathrm{Li}_{2} \mathrm{IrO}_{3}{ }^{1}$ the layers are stacked in an $(\mathrm{a} \gamma \mathrm{b}) \square(\mathrm{c} \beta \mathrm{a}) \square(\mathrm{b} \alpha \mathrm{c}) \square$ fashion where the position of the anion sub-lattice is indicated by small Latin letters, the position of the cation sub-lattice is indicated by small Greek letters, the layers are indicated with round brackets and interlayer voids with " $\square$ ". This stacking order leads to trigonal-antiprismatic, i.e. octahedral, interlayer voids, which are filled with lithium cations. The phase composition of $\alpha-\mathrm{Li}_{2} \mathrm{IrO}_{3}$ can also be given as $\mathrm{Li}_{3}{ }_{3} \mathrm{Li}^{\prime \prime}$ $\mathrm{Ir}_{2} \mathrm{O}_{6}$, where $\mathrm{Li}^{\prime}$ denotes interlayer lithium and Li" denotes intralayer lithium. By acid treatment the interlayer lithium can be exchanged with protons, leading to a $\mathrm{H}_{3}{ }^{\prime} \mathrm{Li}^{\prime \prime} \mathrm{Ir}_{2} \mathrm{O}_{6}$ phase. ${ }^{8}$ In this phase the layers exhibit an $(a \gamma b) \square(b \alpha c) \square(c \beta a) \square$ stacking order, which leads to trigonal-prismatic interlayer voids. Due to the honeycomb motif, several stacking orders exist that lead to trigonal-prismatic interlayer voids. In consequence the stacking order in this phase doesn't need to be homogenous; changes in the direction of stacking order appear as planar defects, i.e. stacking faults. In fact, the crystal structure of $\mathrm{H}_{3} \mathrm{LiIr}_{2} \mathrm{O}_{6}$ was found to be heavily faulted. ${ }^{9}$

The presence of stacking faults is in general a common phenomenon in layered honeycomb iridates that seriously impedes their structural characterization. ${ }^{4,10,11}$ The occurrence of defects causes diffuse scattering that among others can lead 
to strong peak broadening. ${ }^{12}$ In heavily faulted structures broadened reflections merge with the background, which can lead to artificial lower peak intensities, if the peak shapes are not properly modeled. Vast peak broadening may also lead to an artificial higher lattice symmetry, as stacking faults break the translational symmetry and it is therefore impossible to select a unit cell in the corresponding directions. In consequence, if the occurrence of stacking fault disorder and therefore the microstructure of the sample is neglected during the process of the crystal structure solution, an occupational disorder in the intralayer cation sublattice is introduced, which is connected with a higher lattice symmetry. Thus the crystal structure of $\mathrm{H}_{3} \mathrm{LiIr}_{2} \mathrm{O}_{6}$ was first described as a CrOOH-type structure with space group $R \overline{3} m 1$ and with a completely disordered intralayer cation-sublattice. ${ }^{8}$ By considering planar defects and developing a suitable microstructural model, the crystal structure of $\mathrm{H}_{3} \mathrm{LiIr}_{2} \mathrm{O}_{6}$ was further sharpened to a layered honeycomb structure in space group $C 2 / m$ with a completely ordered cation sublattice. ${ }^{9}$ A detailed understanding of the crystal structures of honeycomb lattices is crucial, as $\mathrm{H}_{3} \mathrm{LiIr}_{2} \mathrm{O}_{6}$ was found to be the first materialization of the quantum spin liquid state on a honeycomb lattice, ${ }^{13}$ that may be relevant for the Kitaev quantum spin liquid. ${ }^{7}$ The interlayer protons in $\mathrm{H}_{3} \mathrm{LiIr}_{2} \mathrm{O}_{6}$ which exhibit a linear coordination can be replaced by silver cations. In consequence the interlayer distance is increased and therefore interlayer interactions may be decreased. Furthermore intralayer $\operatorname{Ir}^{4+}$ as a $\mathrm{d}^{5}$ cation can be replaced by $\mathrm{Ru}^{4+}, \mathrm{a} \mathrm{d}^{4}$ cation with a comparable ionic radius $\left(r\left(\operatorname{Ir}^{4+}\right)=0.765 \AA, r\left(\mathrm{Ru}^{4+}\right)=0.760 \AA\right) .{ }^{14}$ This leads to $\mathrm{Ag}_{3} \mathrm{LiIr}_{2} \mathrm{O}_{6}$ $\left(\equiv \mathrm{Ag}\left(\mathrm{Li} \frac{1}{3} \mathrm{I} r_{3}^{2}\right) \mathrm{O}_{2}\right)$ and $\mathrm{Ag}_{3} \mathrm{LiRu}_{2} \mathrm{O}_{6}\left(\equiv \mathrm{Ag}\left(\mathrm{Li} \frac{1}{3} \mathrm{Ru}_{3}^{2}\right) \mathrm{O}_{2}\right)$ phases, that can be considered as modified delafossites ${ }^{15}\left(\mathrm{CuMO}_{2}\right.$ and $\left.\mathrm{AgMO}_{2}\right)^{16,17}$ For these compounds average crystal structure models in space group $R \overline{3} m 1$ with a completely disordered intralayer cation-sublattice have been already reported in the literature ${ }^{18,19}$ The presence of planar defects and a most likely completely honeycomb-like intralayer cation-sublattice was expected for $\mathrm{Ag}_{3} \mathrm{LiIr}_{2} \mathrm{O}_{6}$ by Todorova et al. ${ }^{18}$ The authors derived a microstructure model from recursive DIFFaX ${ }^{20}$ simulations and approximated the diffraction line shapes by anisotropic microstrain broadening models. ${ }^{21,22} \mathrm{~A}$ refinement of the real crystal structure that includes the planar defects, however, could not be carried out.

In this study we describe the solution of the real crystal structure of the layered honeycomb delafossite-type phases $\mathrm{Ag}_{3} \mathrm{LiIr}_{2} \mathrm{O}_{6}$ and $\mathrm{Ag}_{3} \mathrm{LiRu}_{2} \mathrm{O}_{6}$, which also includes the development of suitable microstructure models and their refinement to the measured data.

\section{Experimental section}

\section{Phase synthesis}

The polycrystalline samples of $\mathrm{Ag}_{3} \mathrm{LiRu}_{2} \mathrm{O}_{6}$ and $\mathrm{Ag}_{3} \mathrm{LiIr}_{2} \mathrm{O}_{6}$ were synthesized by ion-exchange reactions from $\mathrm{Li}_{2} \mathrm{RuO}_{3}$ and $\alpha-\mathrm{Li}_{2} \mathrm{IrO}_{3}$ powders, respectively. The precursors were obtained by a solid state reaction using powders of $\mathrm{Li}_{2} \mathrm{CO}_{3}$ and $\mathrm{RuO}_{2}$ or
$\mathrm{IrO}_{2}$. The precursor powder was mixed with a 10 -times excess of $\mathrm{AgNO}_{3}$. The mixture was heated at $240{ }^{\circ} \mathrm{C}$ for 72 hours in an alumina crucible, and cooled to room temperature at a rate of $20 \mathrm{~K}$ per hour. At high-temperatures, the interlayer $\mathrm{Li}^{+}$ions of $\mathrm{Li}_{2} \mathrm{RuO}_{3}$ or $\alpha-\mathrm{Li}_{2} \mathrm{IrO}_{3}$ were replaced with $\mathrm{Ag}^{+}$through the following reactions:

$$
\begin{aligned}
3 \mathrm{AgNO}_{3(\mathrm{l})}+ & 2 \mathrm{Li}_{2} \mathrm{RuO}_{3(\mathrm{~s})}\left(\alpha-\mathrm{Li}_{2} \mathrm{IrO}_{3(\mathrm{~s})}\right) \\
& \rightarrow \mathrm{Ag}_{3} \mathrm{LiRu}(\mathrm{Ir})_{2} \mathrm{O}_{6(\mathrm{~s})}+3 \mathrm{LiNO}_{3(\mathrm{~s})}
\end{aligned}
$$

The product was rinsed with distilled water to remove the excess of $\mathrm{AgNO}_{3}$ and resulting $\mathrm{LiNO}_{3}$, and dried at room temperature.

\section{Phase characterization}

Transmission electron microscopy (TEM). Bulk samples of $\mathrm{Ag}_{3} \mathrm{LiRu}_{2} \mathrm{O}_{6}$ and $\mathrm{Ag}_{3} \mathrm{LiIr}_{2} \mathrm{O}_{6}$ were ground and distributed onto a holey carbon/copper grid. TEM was performed with a Philips CM 30 ST microscope (300 kV, LaB6 cathode) equipped with a spinning star device enabling the use of precession electron diffraction (PED) ${ }^{23}$ Simulations of the diffraction patterns and HRTEM micrographs (multi-slice formalism) were obtained with the JEMS ${ }^{24}$ software package.

Laboratory X-ray powder diffraction. For comparison the XRPD-patterns of the solid phases were collected at room temperature on a laboratory powder diffractometer in DebyeScherrer geometry (Stadi P-Diffractometer (Stoe), Ag- $\mathrm{K}_{\alpha 1}$ radiation from primary $\mathrm{Ge}(111)-J o h a n n-t y p e$ monochromator, Mythen $1 \mathrm{~K}$ detector (Dectris)). Due to the high fluorescence of ruthenium when using silver radiation, the diffraction pattern of $\mathrm{Ag}_{3} \mathrm{LiRu}_{2} \mathrm{O}_{6}$ was also collected using the same type of diffractometer equipped with a Mo-cathode. Each pattern was collected in a $2 \theta$ range of ( 2 to 100$)^{\circ}$ applying a total scan time of $15 \mathrm{~h}$. The samples were sealed in $0.3 \mathrm{~mm}$ diameter borosilicate glass capillaries (Hilgenberg glass no. 14), which were spun during the measurement.

\section{Synchrotron X-ray powder diffraction}

Synchrotron X-ray total scattering patterns of the samples were recorded in Debye-Scherrer mode at the European Synchrotron Radiation Facility (ESRF), Grenoble (France), at a wavelength of $\lambda=0.18087 \AA(\approx 68.5 \mathrm{keV})$ on beamline ID31 in rapid acquisition mode. ${ }^{25}$ Diffracted X-rays were detected using a single photon counting detector (Dectris, Pilatus3X CdTe $2 \mathrm{M}$ with $172 \times 172 \mu \mathrm{m}^{2}$ pixel size) mounted orthogonal to the beam path with a sample-to-detector distance of $273.35 \mathrm{~mm}$. The measured samples were sealed in kapton tubes of $1.0 \mathrm{~mm}$ diameter. The collected Debye-Scherrer rings were subsequently azimuthally integrated with the pyFAI-software $^{26}$ to one-dimensional powder diffraction patterns in $Q\left[\mathrm{~nm}^{-1}\right]$ and $2 \theta\left[^{\circ}\right]$ versus intensity. Parameters for intensity integration were determined from a NIST $\mathrm{CeO}_{2}$ reference sample (SRM 674b). Further mask generation, polarization correction, and azimuthal integration of the 2D patterns was performed using the xpdtools software. ${ }^{27}$ Using the software TOPAS, ${ }^{28}$ Rietveld $^{29}$ refinements were carried out, applying the funda- 


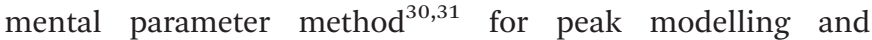
Chebyshev polynomials for modelling the background.

\section{Pair distribution function (PDF) analyses}

PDFGETX $2^{32}$ was used to correct and normalize the diffraction data and the Fourier transform in order to obtain the experimental pair distribution function (PDF), $G(r)$. The $Q$ range used in the Fourier transform was limited to $30 \AA^{-1}$. Nickel was previously measured as a standard material to determine the $Q$-damp and $Q$-broad parameters which are the parameters that correct the PDF envelope function for instrumental resolution effects. $^{33,34}$

\section{Results and discussion}

\section{Phase characterization}

In the diffraction pattern of $\mathrm{Ag}_{3} \mathrm{LiRu}_{2} \mathrm{O}_{6}$, all peaks can be assigned to the title compound. The diffraction pattern of

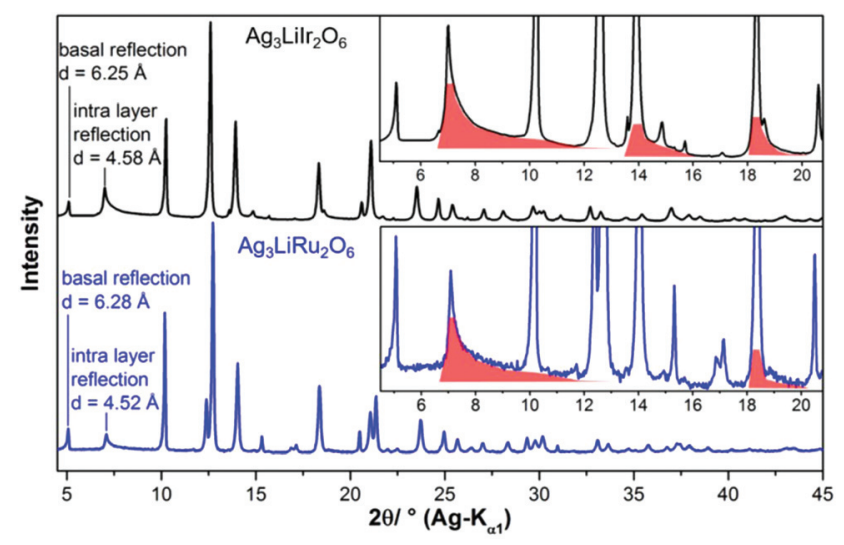

Fig. 1 Comparison of the measured XRPD patterns of $\mathrm{Ag}_{3} \mathrm{Lilr}_{2} \mathrm{O}_{6}$ (black pattern) and $\mathrm{Ag}_{3} \mathrm{LiRu}_{2} \mathrm{O}_{6}$ (blue pattern). Characteristic triangular peak shapes indicating structural disorder are highlighted by red background color. Lattice plane distances of reflections corresponding to inter- and intra-layer distances are given, as well.
$\mathrm{Ag}_{3} \operatorname{LiIr}_{2} \mathrm{O}_{6}$ exhibits weak peaks that can be assigned to elemental silver and to $\alpha-\mathrm{Li}_{2} \mathrm{IrO}_{3}$. The final Rietveld refinement (ESI, Fig. S1 $\dagger$ ) revealed the content of impurities to be very low (1.3 wt $\% \mathrm{Ag}$ and $0.5 \mathrm{wt} \% \alpha-\mathrm{Li}_{2} \mathrm{IrO}_{3}$ ). As expected the isotypic compounds $\mathrm{Ag}_{3} \mathrm{LiIr}_{2} \mathrm{O}_{6}$ and $\mathrm{Ag}_{3} \mathrm{LiRu}_{2} \mathrm{O}_{6}$ show almost identical XRPD patterns (Fig. 1). Slight differences in the reflection positions point to slightly different unit cell metrics. Some reflections show large anisotropic broadening and characteristic triangular peak shapes (red highlighted areas), which is indicative of heavily stacking faulted samples. ${ }^{35} A b$ initio indexing by an iterative use of singular value decomposition ${ }^{36}$ didn't lead to an unambiguous result, as the XRPD pattern can be indexed both with a trigonal unit cell with $P 3_{1}, P 3_{1} 21$ and $P 3_{1} 12$ as most probable space groups or with a monoclinic unit cell with $C 2, C m$ and $C 2 / m$ as most probable space group (Table 1).

\section{Evaluation of the $3 R$-type structure models}

The 3R-type structure models comprise a complete occupational disorder between $\mathrm{Li}$ and $\mathrm{Ru} / \mathrm{Ir}$ and hence a small rhombohedral unit cell in $a$ - and $b$-dimension (Fig. 2, a, black cell edges). A completely ordered intra-layer cation sublattice with a honeycomb motif leads to an expanded unit cell in the $a b$-plane (Table 1), that can be described both by a trigonal (blue cell edges) and a monoclinic cell metric (green cell edges). Pawley fits ${ }^{37}$ were employed in order to evaluate the considered unit cell metrics (Fig. 2b-d). By using the rhombohedral, small unit cell (Fig. 2a, black cell edges) several reflections at $(8.9,19.9 \text { and } 23.9)^{\circ} 2 \theta$ cannot be modeled (Fig. $2 \mathrm{~b},{ }^{*}$ ), which indicates that the cell is too small and/or that the space group symmetry too high to describe the real layer constitution. Both the large trigonal and monoclinic unit cells (Fig. 2a, green and blue cell edges) yield equivalent Pawley fits, in which the reflections at $(8.9,19.9 \text { and 23.9) })^{\circ} 2 \theta$ (Fig. $2 c$ and d) are included.

As Todorova et al. ${ }^{18}$ already described the different cell settings arise from different stacking orders of the layers. The trigonal cell metric with space group $P 3_{1} 21 / P 3_{1} 12$ leads to a circu-

Table 1 Rhombohedral unit cells of the proposed crystal structure models of $\mathrm{Ag}_{3} \mathrm{Lilr}_{2} \mathrm{O}_{6}{ }^{18}$ and $\mathrm{Ag}_{3} \mathrm{LiRu}_{2} \mathrm{O}_{6}{ }^{19}$ and the corresponding transformed, enlarged trigonal and monoclinic settings

\begin{tabular}{|c|c|c|c|c|c|c|}
\hline & \multicolumn{3}{|l|}{$\mathrm{Ag}_{3} \operatorname{LiIr}_{2} \mathrm{O}_{6}$} & \multicolumn{3}{|l|}{$\mathrm{Ag}_{3} \mathrm{LiRu}_{2} \mathrm{O}_{6}$} \\
\hline & $\begin{array}{l}\text { Rhombohedral } \\
\text { cell }\end{array}$ & $\begin{array}{l}\text { Alternative } \\
\text { trigonal cell }\end{array}$ & $\begin{array}{l}\text { Monoclinic } \\
\text { cell }\end{array}$ & $\begin{array}{l}\text { Rhombohedral } \\
\text { cell }\end{array}$ & $\begin{array}{l}\text { Alternative } \\
\text { trigonal cell }\end{array}$ & $\begin{array}{l}\text { Monoclinic } \\
\text { cell }\end{array}$ \\
\hline Space group & $R \overline{3} m 1$ & $P 3_{1} 12 / P 3_{1} 21$ & $C 2 / m$ & $R \overline{3} m 1$ & $P 3_{1} 12 / P 3_{1} 21$ & $C 2 / m$ \\
\hline$V / \AA^{3}$ & 150.7 & 452.1 & 301.4 & 149.5 & 348.5 & 299.0 \\
\hline$Z$ & 1 & 3 & 2 & 1 & 3 & 2 \\
\hline No. of layers & 3 & 3 & 1 & 3 & 3 & 1 \\
\hline$a / \AA$ & 3.0478 & 5.2789 & 5.2789 & 3.0642 & 5.3074 & 5.3074 \\
\hline$b / \AA ̊ ̊$ & 3.0478 & 5.2789 & 9.1434 & 3.0642 & 5.3074 & 9.1926 \\
\hline$c / \AA ̊ ̊$ & 18.7335 & 18.7335 & 6.4877 & 18.3861 & 18.3861 & 6.3789 \\
\hline$\alpha /{ }^{\circ}$ & 90 & 90 & 90 & 90 & 90 & 90 \\
\hline$\beta /{ }^{\circ}$ & 90 & 90 & 105.3 & 90 & 90 & 106.1 \\
\hline$\gamma /{ }^{\circ}$ & 120 & 120 & 90 & 120 & 120 & 90 \\
\hline Stacking vectors & 1 & 3 , circular sequence & 1 & 1 & 3 , circular sequence & 1 \\
\hline Independent sites/layer & 3 & 7 & 6 & 3 & 7 & 6 \\
\hline
\end{tabular}




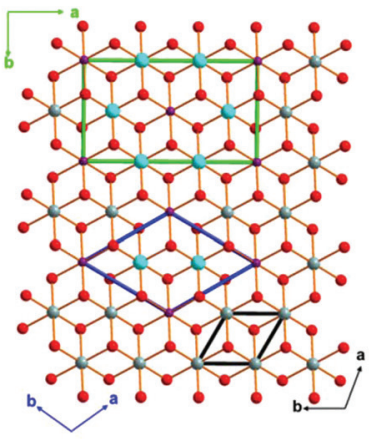

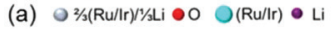

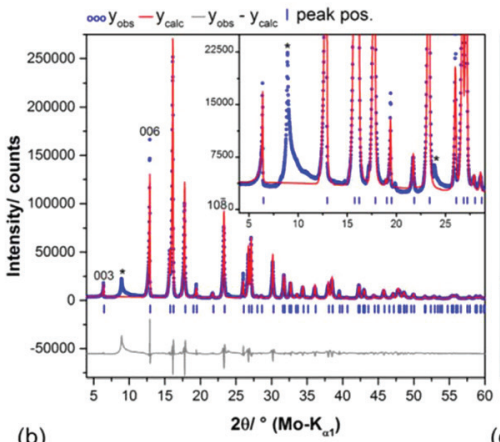

(b)

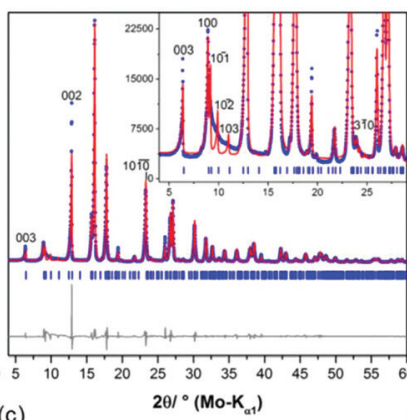

(c)

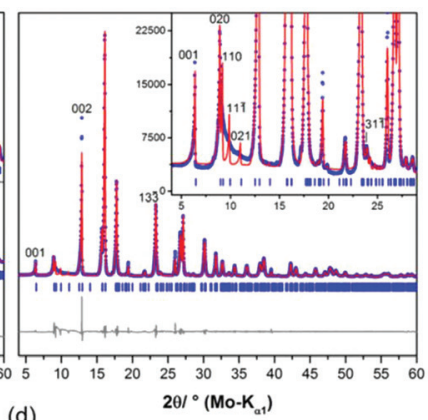

(d) $201^{\circ}\left(\right.$ Mo-K $\left.\mathrm{K}_{\mathrm{a}}\right)$

Fig. 2 (a) Topview on the $\mathrm{Li}(\mathrm{Ru} / \mathrm{Ir})_{2} \mathrm{O}_{6}{ }^{3-}$ layers in the proposed crystal structure models of $\mathrm{Ag}_{3} \mathrm{Lilr}_{2} \mathrm{O}_{6}{ }^{18}$ and $\mathrm{Ag}_{3} \mathrm{LiRu}_{2} \mathrm{O}_{6}{ }^{19}{ }^{19} \mathrm{The}{ }^{1}$-plane of the rhombohedral unit cell, which includes an occupational disorder of $\mathrm{Li}$ and Ir/Ru is indicated by black bars, the ab-plane of the transformed monoclinic unit cell with an ordered, honey-comb lattice cation sublattice is indicated by green bars. Pawley fit of the measured diffraction pattern of $\mathrm{Ag}_{3} \mathrm{LiRu}_{2} \mathrm{O}_{6}$ using the rhombohedral unit cell (space group $R \overline{3} \mathrm{~m} 1$ ) of the proposed structure model (b) with reflections that are not modelled using this unit cell indicated by " $\star$ ", and using the alternative trigonal cell (space group $\left.P 3_{1} 21 / P 3_{1} 12\right)$ (c) and the transformed monoclinic unit cell (space group C2/m) (d) (Table 1).

lar stacking sequence of three stacking vectors, whereas the C-centered monoclinic cell describes a homogenous stacking sequence. Due to the presence of planar defects the coherence of the stacking order is almost lost for both compounds as indicated by the severe broadening of the $10 \overline{1}, 10 \overline{2}$ and the 103 reflection or the $110,11 \overline{1}$ and the 021 reflections, respectively (Fig. 2c and d). Hence we decided to use the monoclinic cell setting for describing the ideal, faultless crystal structures, i.e. primarily the layer constitutions of $\mathrm{Ag}_{3} \mathrm{LiIr}_{2} \mathrm{O}_{6}$ and $\mathrm{Ag}_{3} \mathrm{LiRu}_{2} \mathrm{O}_{6}$, as this unit cell setting contains less symmetrically independent atomic sites per layer (Table 1) and can be therefore refined by using fewer parameters.

\section{Solution and description of the ideal, faultless crystal structures}

XRPD and PDF analyses. An initial model of the ideal faultless structure was obtained by excluding the anisotropically broadened regions of the diffraction patterns: (7.05-9.90, $10.44-12.20,14.40-17.80$ and $18.75-20.40)^{\circ} 2 \theta$ for the Ir-phase and (9.00-12.00, 13.15-15.00, 19.56-21.26 and 23.72-25.60) ${ }^{\circ}$ $2 \theta$ for the Ru-phase. The layer constitution, i.e. the atomic positions of the intra-layer cations and anions in real space, of $\mathrm{H}_{3} \mathrm{LiIr}_{2} \mathrm{O}_{6}{ }^{9}$ was used as a starting model and the $\mathrm{M}-\mathrm{O}$ and $\mathrm{M}-\mathrm{M}$ distances were softly restrained to $\approx 2.0 \AA$ and $\approx 3.0 \AA$ respectively by applying a flat artificial penalty function in order to stabilize the refinements. PDF-analysis (Fig. 4) was used to derive reasonable values for these restraints on the interatomic distances. This procedure led, as described for $\mathrm{H}_{3} \mathrm{LiIr}_{2} \mathrm{O}_{6}{ }^{9}$ to a stable refinement with reproducible results. The crystallographic data have been deposited at the CDCC, deposit numbers: 1912803 and 1912804. $\dagger$

The crystal structures of $\mathrm{Ag}_{3} \mathrm{LiIr}_{2} \mathrm{O}_{6}$ and $\mathrm{Ag}_{3} \mathrm{LiRu}_{2} \mathrm{O}_{6}$ consist of edge sharing $\mathrm{Ir} / \mathrm{RuO}_{6 / 3}$ octahedra forming layers perpendicular to the $c$-axis. Silver cations are situated in-between the layers and are linearly coordinated by two oxide anions with the $\mathrm{O}-\mathrm{Ag}-\mathrm{O}$ bond oriented perpendicular to the layer planes. This leads to an overall $(\mathrm{a} \gamma \mathrm{b}) \beta(\mathrm{b} \alpha \mathrm{c}) \gamma(\mathrm{c} \beta \mathrm{a}) \alpha$ stacking order of the layers (Fig. 3a). The intralayer cation sublattice is completely ordered. Condensed 6-fold rings of edge sharing ( $\mathrm{Ir} / \mathrm{Ru}) \mathrm{O}_{6 / 2}{ }^{2-}$ octahedra form a honey-comb like motif (Fig. 3b, yellow octahedra) and lithium cations occupy the central octahedral voids of the honeycombs (green octahedra). The honeycombs of each layer (Fig. 3c, yellow octahedra) are slightly shifted with respect to the honeycombs of the preceding layer (Fig. 3c, blue octahedra), which leads to an overall staggered stacking. The layer constitutions of $\mathrm{Ag}_{3} \mathrm{LiIr}_{2} \mathrm{O}_{6}$ and $\mathrm{Ag}_{3} \mathrm{LiRu}_{2} \mathrm{O}_{6}$ are comparable to $\mathrm{H}_{3} \mathrm{LiIr}_{2} \mathrm{O}_{6}{ }^{9}$ (ESI, Tables $\mathrm{S} 2$ and $\mathrm{S} 3 \dagger$ ), the interlayer distance, however, is increased from $4.54 \AA$ after replacing the protons by silver cations to $6.25 \AA$ (Ir-phase) and $6.28 \AA$ (Ruphase), respectively.

In Fig. 4a comparison of the PDF-curves of $\mathrm{Ag}_{3} \mathrm{LiIr}_{2} \mathrm{O}_{6}$ (black curve) and $\mathrm{Ag}_{3} \mathrm{LiRu}_{2} \mathrm{O}_{6}$ (blue curve) is presented. The radial distribution functions are essentially identical for both isotypic phases. Up to a radial distance of $5.3 \AA$ all peaks in the PDF-curves can be assigned to intralayer atom pairs (grey background). Within the resolution of the PDF-curves $\mathrm{Ag}_{3} \mathrm{LiIr}_{2} \mathrm{O}_{6}$ and $\mathrm{Ag}_{3} \mathrm{LiRu}_{2} \mathrm{O}_{6}$ exhibit identical M-O (2.0(1) $\AA$ ),

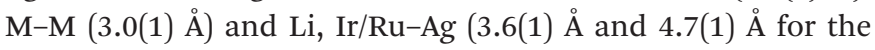
second nearest neighbor) distances. Slight differences can be observed for the $\mathbf{M}-\mathrm{M}^{\prime \prime}$ (second nearest neighbor) distances within the $a b$-plane, that are slightly larger in $\mathrm{Ag}_{3} \operatorname{LiIr}_{2} \mathrm{O}_{6}(5.3$ (1) $\AA$ and 6.1(1) $⿱$ ) than in $\mathrm{Ag}_{3} \mathrm{LiRu}_{2} \mathrm{O}_{6}$ (5.2(1) $\AA$ and 6.0(1) $)$. This is also reflected by the larger $a$ - and $b$-lattice parameters of the Ir-phase ( $a=5.287$ (1) $\AA, b=9.151(2) \AA$ versus $a=5.226(1)$ $\AA, b=9.036(1) \AA$ for the Ru-phase, ESI, Table S2 $\dagger$ ) and can be explained by the slightly larger ionic radius of $\operatorname{Ir}^{4+}$ (see Introduction).

\section{Derivation and optimization of a faulting model for the structures of the honeycomb materials}

Development of a microstructural model. The development of a microstructural model for $\mathrm{Ag}_{3} \mathrm{LiIr}_{2} \mathrm{O}_{6}$ and $\mathrm{Ag}_{3} \mathrm{LiRu}_{2} \mathrm{O}_{6}$, i.e. the derivation of possible alternative stacking orders from the layer constitution, was carried out analogously to $\mathrm{H}_{3} \mathrm{LiIr}_{2} \mathrm{O}_{6}{ }^{9}$ 
(a)

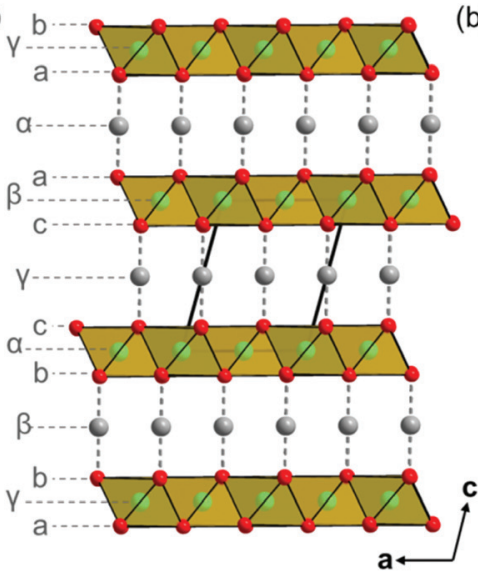

(b)

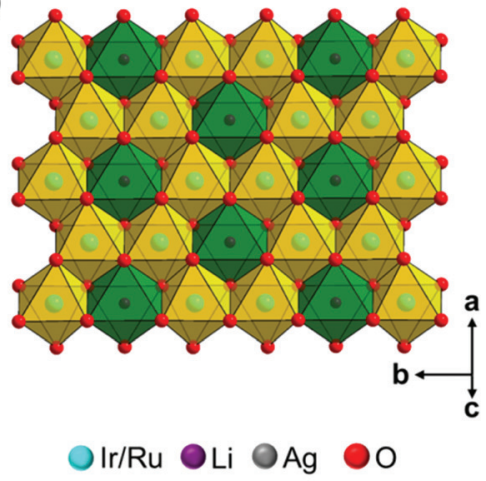

(c)

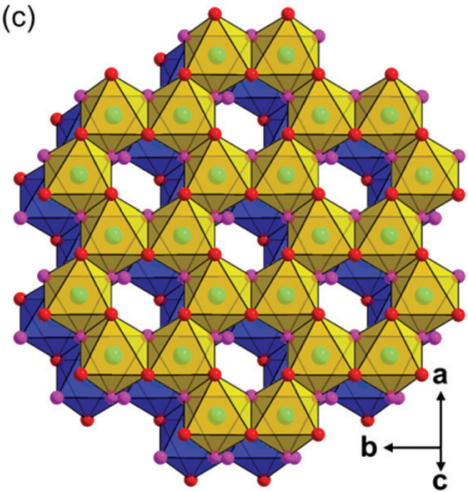

Fig. 3 (a) Packing diagram of the crystal structures of isotypic $\mathrm{Ag}_{3} \mathrm{Lilr}_{2} \mathrm{O}_{6}$ and $\mathrm{Ag}_{3} \mathrm{LiRu}_{2} \mathrm{O}_{6}$ with the stacking sequence of the cation sublattice indicated by small Greek letters and of the anion sublattice by Latin letters. (b) Top view on a honeycomb $\mathrm{Li}(\mathrm{Ir} / \mathrm{Ru})_{2} \mathrm{O}_{6}$-layer, Ir/RuO $\mathrm{O}_{6 / 3}$ octahedra are presented in yellow and $\mathrm{LiO}_{6 / 3}$ octahedra are presented in green. (c) Top view on the stacking of two honeycomb layers, the bottom layer is indicated by blue octahedra and the upper layer is indicated by yellow octahedra, the lithium and silver ions were omitted for clarity. The oxygen atoms of the upper-site of the bottom layer and the oxygen atoms of the bottom-site of the upper layer are presented in magenta.

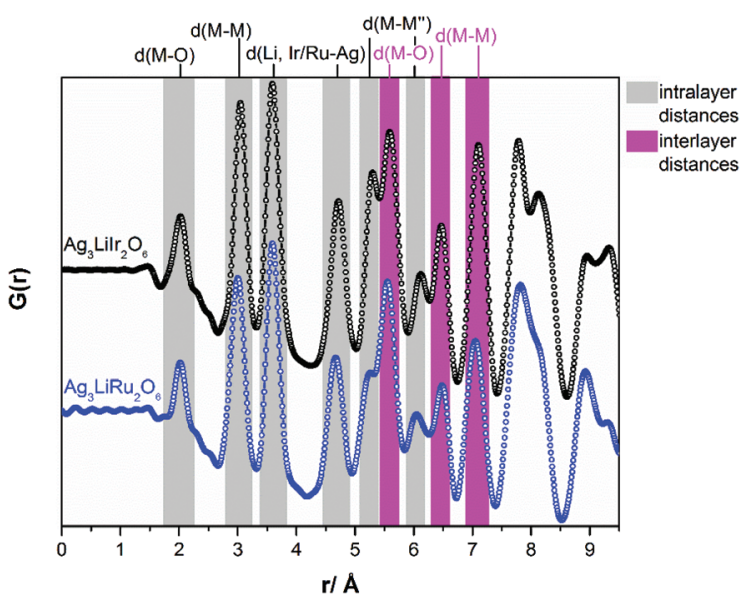

Fig. 4 Measured PDF-curves of $\mathrm{Ag}_{3} \mathrm{Lilr}_{2} \mathrm{O}_{6}$ and $\mathrm{Ag}_{3} \mathrm{LiRu}_{2} \mathrm{O}_{6}$ including the assignment of selected peaks.

The stacking order of the honeycomb-layer is governed by the linear $\mathrm{O}-\mathrm{Ag}-\mathrm{O}$ bond, which is oriented perpendicular to the layer plane. In the ideal, faultless structure model, the stacking sequence is homogenous and can be described by the stacking vector $\mathrm{S1}$. This leads to two types of $\mathrm{O}-\mathrm{Ag}-\mathrm{O}$ bonds: $4 \times \mathrm{O}(2)-\mathrm{Ag}$ (1) $-\mathrm{O}(2)$ and $2 \times \mathrm{O}(1)-\mathrm{Ag}(2)-\mathrm{O}(1)$ (Fig. $5 \mathrm{a}$ and b). Alternative layer stacking sequences with stacking vectors S2-1, S2-2, S2-3 and S2-4 (Fig. 5a) lead to similar O-Ag-O bonds: $2 \times \mathrm{O}(2)-\mathrm{Ag}$. (1) $-\mathrm{O}(2), 2 \times \mathrm{O}(2)-\mathrm{Ag}(1)-\mathrm{O}(1)$ and $2 \times \mathrm{O}(1)-\mathrm{Ag}(2)-\mathrm{O}(2)$, which is also favorable (Fig. 5c-f). Hence the alternative stacking vectors S2-1 to S2-4 can be derived by taking the stacking vector $\mathbf{S} 1$ and the relative shift from an $\mathrm{O}(1)$-site towards the neighboring $\mathrm{O}(2)$-sites into account. There are six neighboring $\mathrm{O}(2)$-sites, but two pairs are identical due to translational symmetry (Fig. 5, black unit cell edges), which leads to four alternative stacking vectors.
In order to describe the microstructures of the samples, all considered layer-to-layer transitions are associated with a transition probability, which is presented in a $5 \times 5$ transition probability matrix in Table 2 . Without any constraints this matrix would contain 25 transition probabilities, i.e. 25 independent parameters which need to be optimized to model the microstructure of each investigated sample. For simplification and reduction of the parameter space it was assumed that all possible $\mathrm{O}-\mathrm{Ag}-\mathrm{O}$ bonds and therefore all considered stacking sequences are equally favorable. Then the transition probability matrix can be described by using only one parameter, $P_{x}$, which describes a general degree of faulting, i.e. the probability that a shift from any of the considered stacking orders to another stacking pattern occurs. This leads to the constrained, diagonal transition probability matrix, presented in Table 2. A faultless structure is modelled by the parameter value $P_{x}=0$, whereas $P_{x}=0.8$ describes stacking in a completely random fashion, i.e. the total loss of coherence in the stacking order, is described and $P_{x}=1.0$ results in a change of the stacking vector after each layer-to-layer transition.

PED and HRTEM investigation. PED patterns of $\mathrm{Ag}_{3} \mathrm{LiIr}_{2} \mathrm{O}_{6}$ and $\mathrm{Ag}_{3} \mathrm{LiRu}_{2} \mathrm{O}_{6}$ are presented in Fig. 6. In both patterns diffuse scattering occurring as streaks (b, e) indicate the presence of planar defects. The remaining sharp reflections are in accordance with simulated patterns along the [110] (a, d) and [100] (c, f) zone axes. In particular in PED pattern of the $\mathrm{Ag}_{3} \mathrm{LiRu}_{2} \mathrm{O}_{6}$ there are some white spots within the streaks, indicating the remains of sharp reflections. The position of these spots in relation to the non-broadened reflections indicate that the PED pattern was collected along the [110] zone axis (ESI, Fig. S2 $\dagger$ ).

In order to visualize the faults in the crystal structures of the title compounds HRTEM images were recorded for the [110] zone axis. The micrographs are in good accordance with the simulated images based on the monoclinic structure 


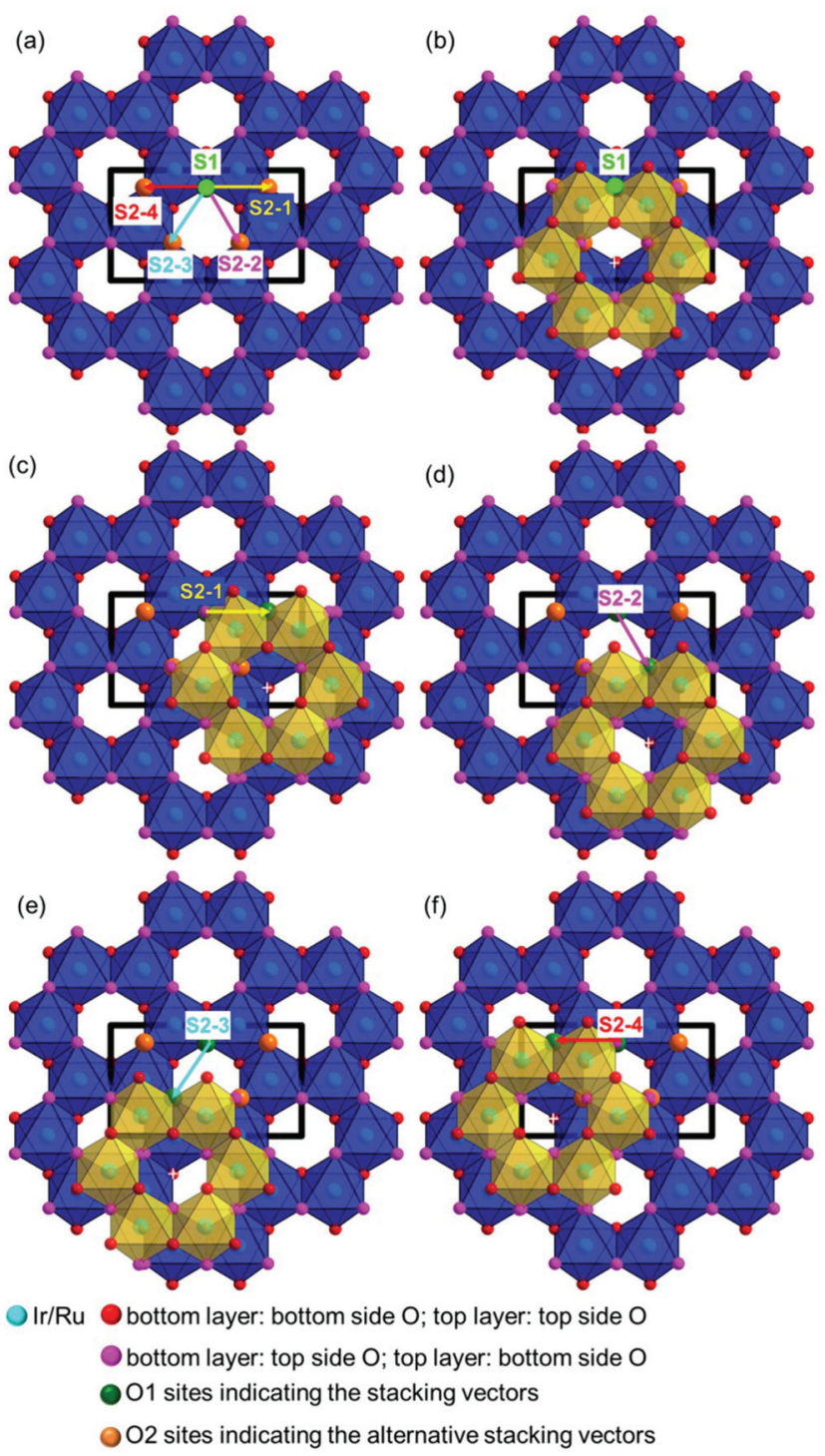

Fig. 5 Derivation of possible stacking vector components from the layer constitution considering interlayer $\mathrm{O}-\mathrm{Ag}-\mathrm{O}$ contacts and the stacking vector $\mathbf{S 1}=$ [001] from the faultless crystal structure model. The bottom layer is indicated by blue octahedra and the top layer by yellow octahedra. (a) Overview of the considered stacking vector components, $(b-f)$ stacking of the honeycomb layers by applying these vectors.

model (ESI, Fig. S3†). HRTEM images of $\mathrm{Ag}_{3} \mathrm{LiRu}_{2} \mathrm{O}_{6}$ using different Defocus values $(\Delta f=(+70,-35$ and -90$) \mathrm{nm})$ are shown in Fig. 7a-c and an HRTEM images of $\mathrm{Ag}_{3} \operatorname{LiIr}_{2} \mathrm{O}_{6}$ is pre-

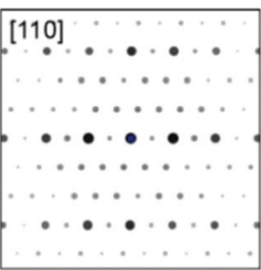

(a)

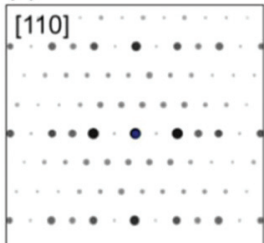

(d)

Fig. 6 Simulated (a, c, d, f) and measured (b, e) PED patterns of $\mathrm{Ag}_{3} \mathrm{Lilr}_{2} \mathrm{O}_{6}(\mathrm{a}-\mathrm{c})$ and $\mathrm{Ag}_{3} \mathrm{LiRu}_{2} \mathrm{O}_{6}(\mathrm{~d}-\mathrm{f})$.

sented in the ESI, Fig. S4. $\dagger$ For $\Delta f=-35 \mathrm{~nm}$ the imaging conditions are close to the Scherzer focus (Fig. 7b), therefore the horizontal dark lines are correlated with the layers of silver cations in the crystal structure and the dark, ellipsoid shaped spots correlate with neighboring ruthenium cations of the intra-layer cation sublattice (Fig. $7 \mathrm{~d}$ ). Within the $\mathrm{LiRu}_{2} \mathrm{O}_{6}{ }^{3-}$ layers circular, bright spots are apparent that can be assigned to the lithium sites, which confirms the presence of an ordered intra-layer cation sublattice. By inspecting the relative position of the dark and bright spots from one layer to subsequent ones it becomes obvious that the stacking order of the layers is not homogenous (Fig. 7b and d, yellow, cyan and green arrows). This is also confirmed by HRTEM micrographs taken with $\Delta f=(+70$ and -90$) \mathrm{nm}$ (Fig. 7a and c). In the micrographs the layers are shifted to the left hand site (green arrows) or to the right hand site (Fig. 7, magenta arrows) with respect to the preceding layer and some layers are situated at the same horizontal position (yellow arrows). This is in accordance with the derived stacking vectors (Fig. 8a). Due to the translational symmetry of the unit cell within the $a b$-plane, there are several possibilities to orient the stacking vectors, in particular the vectors S2-2, S2-3 and S2-4 (Fig. 8b). When the unit cell is rotated in a way that the [110] axis is oriented vertically (Fig. 8c), it becomes clear that the pairs of the stacking vectors (S2-2 and S2-4) and (S2-1 and S2-3) yield the same shift perpendicular to the [110] axis. As the HRTEM image along the [110] zone axis represents a one-dimensional projection of the planar defects, both the stacking vectors S2-2 and S2-4

Table 2 Transition probability matrix for the optimization of the microstructures of stacking faulted $\mathrm{Ag}_{3} \mathrm{LiRu}_{2} \mathrm{O}_{6}$ and $\mathrm{Ag}_{3} \mathrm{Lilr}_{2} \mathrm{O}_{6}$. The $\mathrm{Tarameter}_{\mathrm{x}}$ describing the degree of faulting, was introduced as a global constraint

\begin{tabular}{|c|c|c|c|c|c|}
\hline From $\downarrow /$ to $\rightarrow$ & $\mathrm{O} 1-\mathrm{Ag}-\mathrm{O} 1$ contact & $\mathrm{O} 1-\mathrm{Ag}-\mathrm{O} 2$ contact -1 & $\mathrm{O} 1-\mathrm{Ag}-\mathrm{O} 2$ contact- 2 & $\mathrm{O} 1-\mathrm{Ag}-\mathrm{O} 2$ contact- 3 & $\mathrm{O} 1-\mathrm{Ag}-\mathrm{O} 2$ contact- 4 \\
\hline $\mathrm{O} 1-\mathrm{Ag}-\mathrm{O} 2$ contact -1 & $0.25 \cdot P_{x}, \mathrm{~S} 1$ & $1-P_{x}, \mathrm{~S} 2-1$ & $0.25 \cdot P_{x}, \mathrm{~S} 2-2$ & $0.25 \cdot P_{x}, \mathrm{~S} 2-3$ & $0.25 \cdot P_{x}, \mathrm{~S} 2-4$ \\
\hline $\mathrm{O} 1-\mathrm{Ag}-\mathrm{O} 2$ contact -4 & $0.25 \cdot P_{x}, \mathrm{~S} 1$ & $0.25 \cdot P_{x}, \mathrm{~S} 2-1$ & $0.25 \cdot P_{x}, \mathrm{~S} 2-2$ & $0.25 \cdot P_{x}, \mathrm{~S} 2-3$ & $1-P_{x}, \mathrm{~S} 2-4$ \\
\hline
\end{tabular}




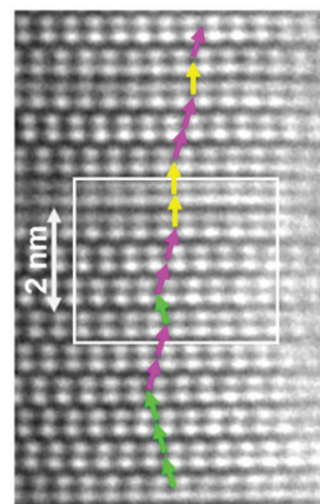

(a) $\Delta \mathrm{f}=+70 \mathrm{~nm}$

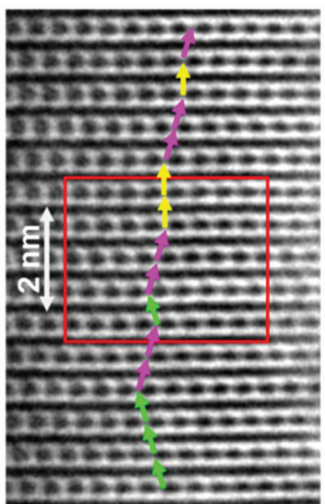

(b) $\Delta \mathrm{f}=-35 \mathrm{~nm}$

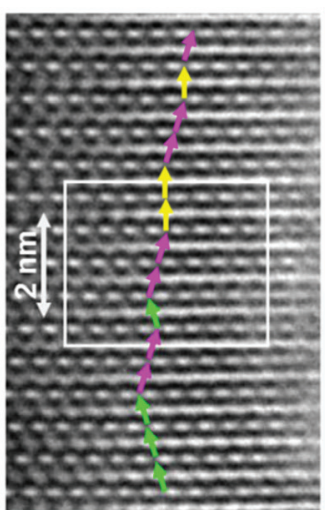

(c) $\Delta f=-90 \mathrm{~nm}$

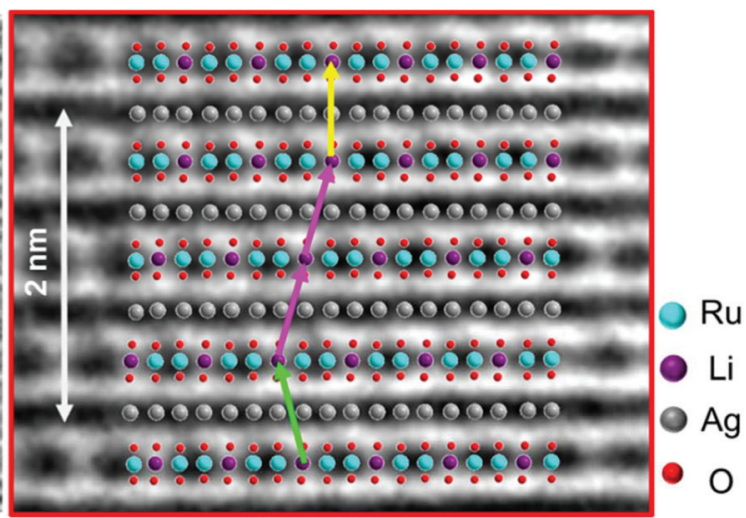

(d)

$\Delta f=-35 n m$

Fig. 7 (a-c) HRTEM micrographs of $\mathrm{Ag}_{3} \mathrm{LiRu}_{2} \mathrm{O}_{6}$ along zone axis [110], assumed thickness $5.22 \mathrm{~nm}$ and (d) overlay of a supercell of $\mathrm{Ag}_{3} \mathrm{LiRu}_{2} \mathrm{O}_{6}$ with an excerpt of HRTEM micrograph (b). Stacking vectors are indicated by yellow, green and cyan arrows.

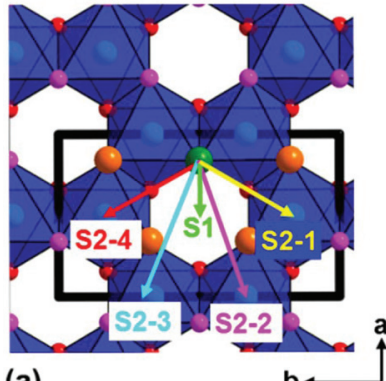

(a)

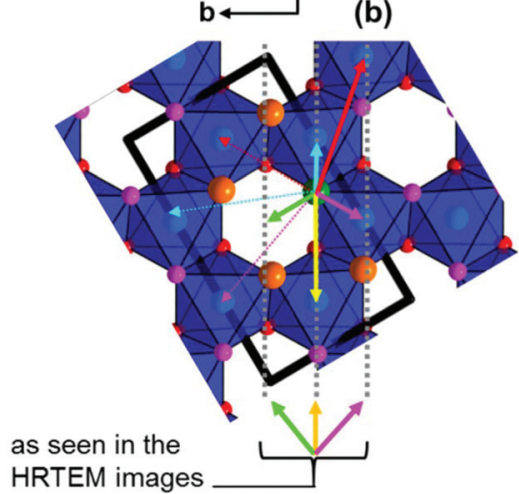

[110]

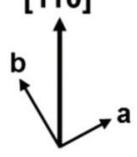

(c)

HRTEM images

Fig. 8 (a) Representation of the stacking vectors, as derived from the possible $\mathrm{O}-\mathrm{Ag}-\mathrm{O}$ contacts (Fig. 5), (b) replacement of the stacking vectors S2-2, S2-3 and S2-4 (dashed arrows) by alternative settings that are equivalent by translational symmetry (straight arrows), (c) reorientation of the unit cell (bold black lines) leading to a vertical orientation of the [110] axis and indication of stacking vectors leading to the same layer shift as observed in the HRTEM image taken along the [110] zone axis (Fig. 7d).

appear as a shift of the layers to the right hand or to the left hand site. Accordingly, the stacking vector S1 appears as a shift to the other site and the stacking vectors S2-1 and S2-3 don't appear as a shift in the HRTEM image, as they lead to a shifting of the layers, perpendicular to the image plane.

A combined approach of grid search and parameter refinement. The refinement of the real crystal structure of stacking faulted substances can be successfully performed by using supercell approaches. ${ }^{38-41}$ In the crystal structures of $\mathrm{Ag}_{3} \mathrm{LiIr}_{2} \mathrm{O}_{6}$ and $\mathrm{Ag}_{3} \mathrm{LiRu}_{2} \mathrm{O}_{6}$ the $\mathrm{O}-\mathrm{Ag}-\mathrm{O}$ bond has not to be exactly perpendicular to the layer plane, as already pointed out by Todorova $e t$ al. ${ }^{18}$ The drawback of algorithms taking small, random, turbostratic like dislocations of the layers into account ${ }^{39,41,42}$ is that they can quickly lead to an over-extension of the parameter-space. Hence, only semi-quantitative information can be extracted, i.e. the transition probabilities cannot be optimized directly. In addition, the layer constitution should not be optimized simultaneously due to the mentioned potential overextension of the parameter space. Recently, a routine was published for the TOPAS software, which enables recursive-like DIFFaX-like simulations and fitting of stacking faulted samples, by creating a number of stacking sequences through supercells and averaging them. ${ }^{43}$ Combining this routine with python scripts enables the iterative variation of the applied transition probabilities, while executing the input file multiple times and thus performing a grid-search optimization in the parameter-space of the transition probabilities. ${ }^{40}$ This can also be realized purely in TOPAS by using the run-number as a running index (ESI, Table S4.†), as it is suggested for performing a series of simulations. ${ }^{44}$

For the optimization of the microstructures of $\mathrm{Ag}_{3} \mathrm{LiIr}_{2} \mathrm{O}_{6}$ and $\mathrm{Ag}_{3} \mathrm{LiRu}_{2} \mathrm{O}_{6}$ the monoclinic unit cells of the initial faultless structure models were transformed into P1-pseudo-orthorhombic cells as described for $\mathrm{H}_{3} \mathrm{LiIr}_{2} \mathrm{O}_{6} \cdot{ }^{9}$ During each simulation 100 supercells with 200 layers each were simulated and averaged. The simulated pattern was refined against the measured pattern while keeping all parameters fixed except the scaling factor. A series of simulations comprised 101 simulated and refined patterns and took between one and two hours using a conventional desk top PC or notebook. During a grid search the transition probability, $P_{x}$, was increased from 0 to 1 in 0.01 increments. In order to sharpen the model of the layer constitution, the atomic positions and also the stacking vectors were refined subsequently, by averaging 100 randomly created stacks of 200 layers using the transition probability $P_{x}$, 


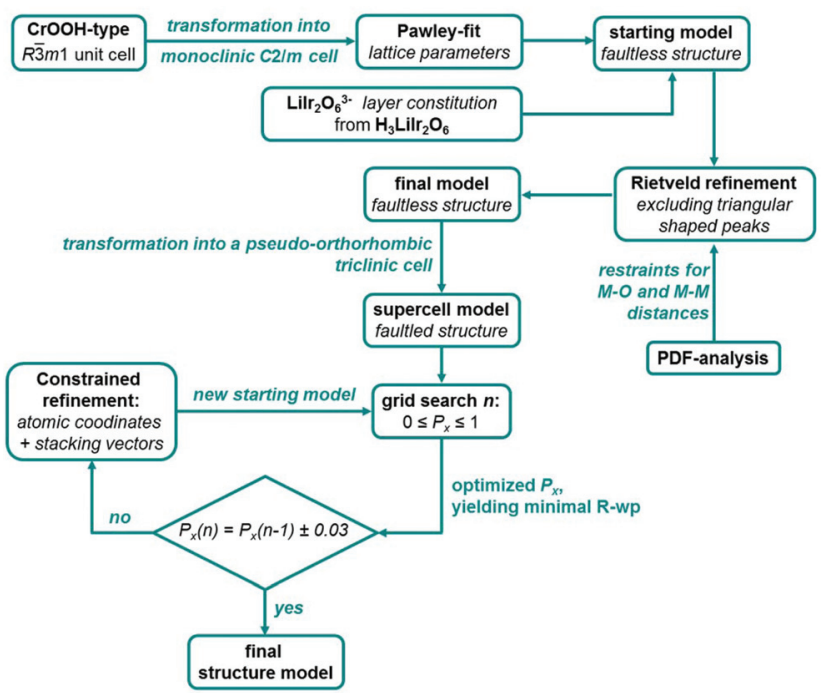

Fig. 9 Schematic illustration of the combined approach of a grid search in the parameter space of the transition probabilities and of least squares based refinement of structural parameter to solve and optimize the crystal structures of $\mathrm{Ag}_{3} \mathrm{Lilr}_{2} \mathrm{O}_{6}$ and $\mathrm{Ag}_{3} \mathrm{LiRu}_{2} \mathrm{O}_{6}$. The constraints applied for the refinement of atomic coordinates and the stacking vectors are given in the ESI, Table S5. $\dagger$

that yielded the best fit, and applying constraints to keep the monoclinic symmetry of the layers (ESI, Table S5†). Afterwards, another grid search was started with the optimized layer constitution. This process was repeated until the actual grid search cycle led to an optimized transition probability that was in a \pm 0.03 range of the optimized transition probability of the previous cycle. For both substances the subsequent optimization of the atomic positions, the stacking vectors and the transition probabilities took between two and three cycles in total. It should be noted, that in each case the refined layer constitution doesn't deviate significantly from the initial model in terms of atomic positions and distances. The whole process of the structural characterization of $\mathrm{Ag}_{3} \mathrm{LiIr}_{2} \mathrm{O}_{6}$ and $\mathrm{Ag}_{3} \mathrm{LiRu}_{2} \mathrm{O}_{6}$ is presented as a scheme in Fig. 9.

Comparison of the microstructures of $\mathrm{Ag}_{3} \operatorname{LiIr}_{2} \mathrm{O}_{6}$ and $\mathbf{A g}_{3} \mathbf{L i R u}_{2} \mathbf{O}_{6}$. In Fig. 10 the graphical results of the final Rietveld refinements of $\mathrm{Ag}_{3} \mathrm{LiIr}_{2} \mathrm{O}_{6}$ (a) and $\mathrm{Ag}_{3} \mathrm{LiRu}_{2} \mathrm{O}_{6}$ (b) using the optimized supercell models are presented. A comparison of Rietveld refinements using the faultless structure and supercell structural model is shown in the ESI, Fig. S1. $\dagger$ The faultless structural models create remarkable misfits in the regions of the anisotropically broadened, triangular shaped peaks (ESI, Fig. S1, $\uparrow$ violett and green, dashed lines). Using the supercell models led to a proper fitting of these peaks (ESI, Fig. S1, $\uparrow$ red and grey, straight lines) without applying any anisotropic microstrain broadening model. ${ }^{21,22}$ The overall fits of the diffraction patterns of the investigated phases show good agreement factors (ESI, Table S1†). Slight deviations can be explained by the fact that, small random dislocations of the layers were completely neglected and that the constraints that were applied to the transition probability matrix (Table 2) are also simplifying the real microstructure to
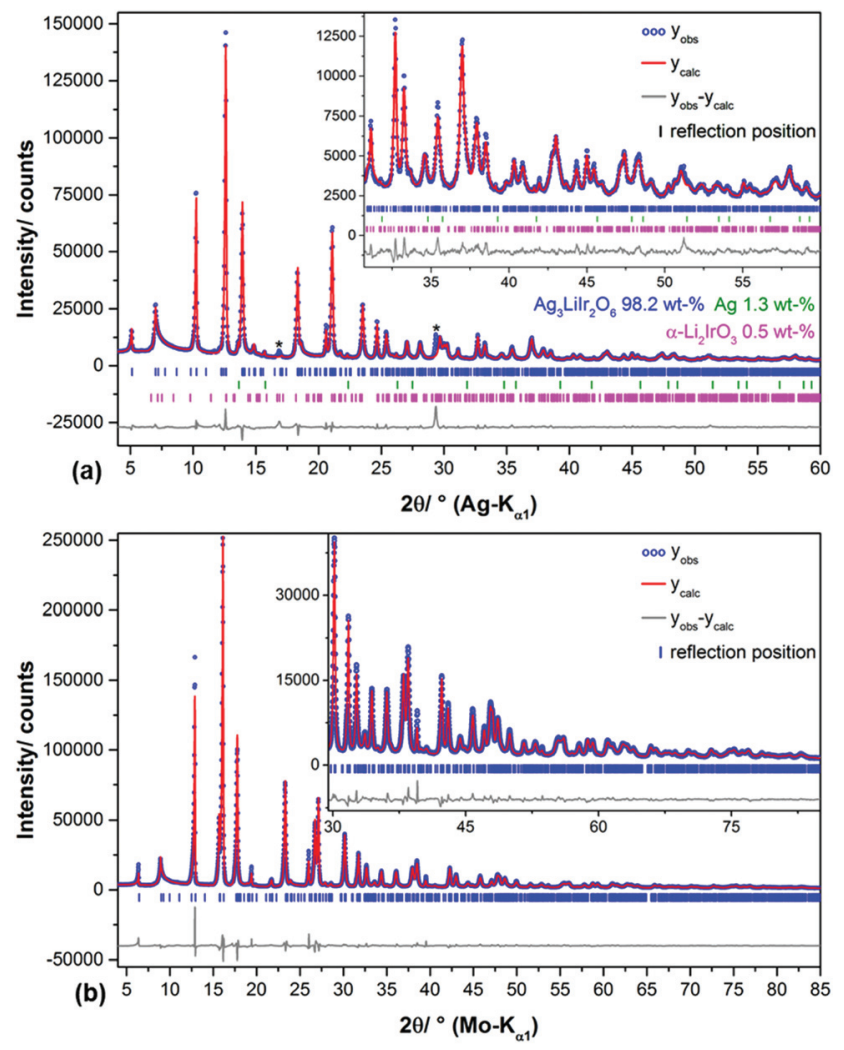

Fig. 10 Rietveld plots of the crystal structure refinements of $\mathrm{Ag}_{3} \mathrm{Lilr}_{2} \mathrm{O}_{6}$ (a) and $\mathrm{Ag}_{3} \mathrm{LiRu}_{2} \mathrm{O}_{6}$ (b) by using the using supercell models with optimized faulting probabilities. Artificial peaks caused by the instrument are indicated by "*".

some extent. Nevertheless, the applied approach for the determination and the refinement of the real and the microstructure of the materials is a suitable approximation. Further extension of the parameter-space would only lead to small improvements of the fits at the expense of an increased parameter correlation.

In Fig. 11 the final $P_{x}$-grids of $\mathrm{Ag}_{3} \mathrm{LiIr}_{2} \mathrm{O}_{6}$ and $\mathrm{Ag}_{3} \mathrm{LiRu}_{2} \mathrm{O}_{6}$ are presented. Increasing the degree of disorder initially leads to a steep decrease of the $R$-wp value. Both grids exhibit a flat minimum at high degrees of disorder. The minimum $R$-wp value is achieved for $\mathrm{Ag}_{3} \mathrm{LiIr}_{2} \mathrm{O}_{6}$ at $P_{x}=0.73$ and for $\mathrm{Ag}_{3} \mathrm{LiRu}_{2} \mathrm{O}_{6}$ at $P_{x}=0.82$. It must be noted that the creation of the stacking sequences is driven by a random number generator. As only a limited number of structures were averaged, the $R$-wp can vary in a small range when a bunch of supercell models is simulated by using the same $P_{x}$-parameter. Taking the flat global minimum of the parameter-space (Fig. 11, inset) into account, it is reasonable to rather use a range than a discrete value for the optimized degree of faulting, $P_{x}$. In consequence the optimized degree of disorder should be given for $\mathrm{Ag}_{3} \mathrm{LiIr}_{2} \mathrm{O}_{6}$ as $P_{x}=0.73 \pm 0.03$ and for $\mathrm{Ag}_{3} \mathrm{LiRu}_{2} \mathrm{O}_{6}$ as $P_{x}=0.82 \pm$ 0.03 .

As both phases are vastly disordered, the coherence of the stacking order of the layers is almost completely lost. The fault probabilities are close to a complete random stacking of the 


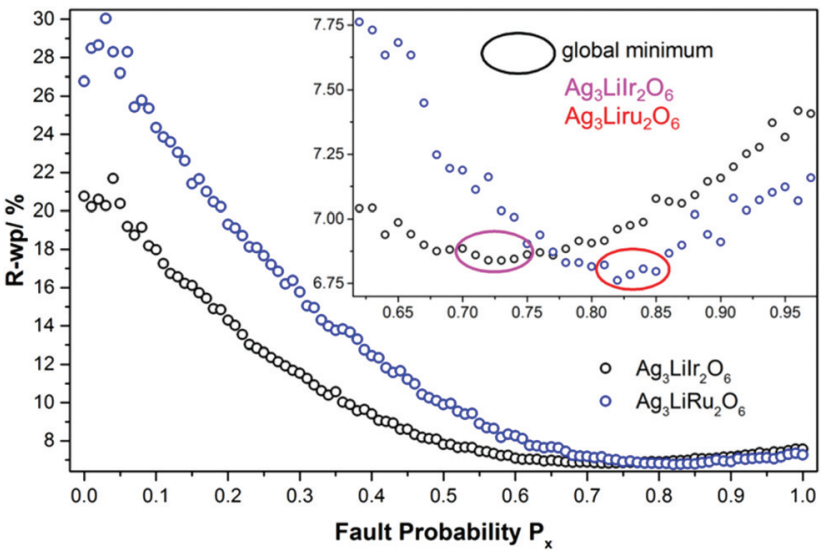

Fig. 11 Evolution of the $R$-wp value in dependence on the fault probability $P_{x}$ that was varied in the grid-search optimizations of the microstructures of $\mathrm{Ag}_{3} \mathrm{Lilr}_{2} \mathrm{O}_{6}$ and $\mathrm{Ag}_{3} \mathrm{LiRu}_{2} \mathrm{O}_{6}$. The global minima of the parameter spaces are highlighted in the insets.

layers, which is represented by $P_{x}=0.8$. Therefore the occurrence of large (more than 3 layers, i.e. more than $2 \mathrm{~nm}$ ) homogenously stacked sections is unlikely for both compounds, as it is reflected by the HR-TEM images (Fig. 7). A higher fault probability than $P_{x}=0.8$ corresponds to a partial anti-correlation of the layer stacking, i.e. stacking in an alternating or circular sequence, which leads to more coherent scattering is more likely. The microstructural properties of $\mathrm{Ag}_{3} \operatorname{LiIr}_{2} \mathrm{O}_{6}$ and $\mathrm{Ag}_{3} \mathrm{LiRu}_{2} \mathrm{O}_{6}$ are similar to $\mathrm{H}_{3} \mathrm{LiIr}_{2} \mathrm{O}_{6} .{ }^{9}$ This may point to the fact that the presence of planar defects is an intrinsic property of this kind of layered honeycomb structures.

\section{Conclusions}

$\mathrm{Ag}_{3} \mathrm{LiIr}_{2} \mathrm{O}_{6}$ and $\mathrm{Ag}_{3} \mathrm{LiRu}_{2} \mathrm{O}_{6}$ were synthesized by ion exchange in an $\mathrm{AgNO}_{3}$ melt. The crystal structures of the layered honeycomb materials were investigated by high resolution laboratory X-ray powder diffraction, pair distribution analysis based on synchrotron powder diffraction and transmission electron microscopy. In the XRPD patterns anisotropic peak broadening and characteristic trigonal peak shapes indicate the presence of planar defects in the crystal lattice, which can be also visualized by HRTEM micrographs. Idealized models of the layered crystal structures were obtained by using the constitution of $\mathrm{LiIr}_{2} \mathrm{O}_{6}{ }^{3-}$ layers of the related phase $\mathrm{H}_{3} \mathrm{LiIr}_{2} \mathrm{O}_{6}$ as a starting model, excluding the section from the diffraction pattern, that are governed by diffuse scattering and extracting reasonable restraints for the bond lengths from the measured PDF curves. The $\mathrm{LiIr}_{2} \mathrm{O}_{6}{ }^{3-}$ and $\mathrm{LiRu}_{2} \mathrm{O}_{6}{ }^{3-}$ layers of the title compounds consist of edge sharing $(\mathrm{Ir} / \mathrm{Ru}) \mathrm{O}_{6 / 3}$ octahedra forming a honeycomb like motif and lithium cations occupy the central octahedral voids of the honeycombs. Linear $\mathrm{O}-\mathrm{Ag}-\mathrm{O}$ bonds connect the layers with each other, leading to an $(\mathrm{a} \gamma \mathrm{b}) \beta(\mathrm{b} \alpha \mathrm{c}) \gamma(\mathrm{c} \beta \mathrm{a}) \alpha$ stacking order of the layers. As different orientations of the honeycomb-layers can lead to this kind of staggered stacking, possible faults, i.e. alternative stacking orders were derived from the layer constitution. A microstructural model was developed and refined against the measured diffraction patterns by applying a grid search optimization in the space of the microstructure-related parameters. Further refinement of the atomic coordinates and the stacking vectors were performed subsequently. Both $\mathrm{Ag}_{3} \operatorname{LiIr}_{2} \mathrm{O}_{6}$ and $\mathrm{Ag}_{3} \mathrm{LiRu}_{2} \mathrm{O}_{6}$ are heavily faulted. In both compounds the layers are stacked in an almost complete random fashion. Therefore the microstructures of the title compounds exhibit great similarities to the microstructure of $\mathrm{H}_{3} \mathrm{LiIr}_{2} \mathrm{O}_{6}$.

\section{Conflicts of interest}

There are no conflicts to declare.

\section{Acknowledgements}

Maxwell W. Terban from the Max Planck Institute of solid state research is gratefully acknowledged for his valuable support in performing the synchrotron powder diffraction experiment and in the related data processing. The high energy powder diffraction patterns were collected at ID31 beamline at the ESRF in the frame of in-house research program. Open Access funding provided by the Max Planck Society.

Funding by DFG for the project "In search of structure" (grant EG 137/9-1) is gratefully acknowledged.

\section{References}

1 M. J. O'Malley, H. Verweij and P. M. Woodward, J. Solid State Chem., 2008, 181, 1803-1809.

2 T. Takayama, A. Kato, R. Dinnebier, J. Nuss, H. Kono, L. S. I. Veiga, G. Fabbris, D. Haskel and H. Takagi, Phys. Rev. Lett., 2015, 114, 077202.

3 H. Takagi, T. Takayama, G. Jackeli, G. Khaliullin and S. E. Nagler, Nat. Rev. Phys., 2019, 1, 264-280.

4 D. C. Wallace and T. M. McQueen, Dalton Trans., 2015, 44, 20344-20351.

5 Y. Singh and P. Gegenwart, Phys. Rev. B: Condens. Matter Mater. Phys., 2010, 82, 064412.

6 Y. Singh, S. Manni, J. Reuther, T. Berlijn, R. Thomale, W. Ku, S. Trebst and P. Gegenwart, Phys. Rev. Lett., 2012, 108, 127203.

7 A. Kitaev, Ann. Phys., 2006, 321, 2-111.

8 M. J. O'Malley, P. M. Woodward and H. Verweij, J. Mater. Chem., 2012, 22, 7782.

9 S. Bette, T. Takayama, K. Kitagawa, R. Takano, H. Takagi and R. E. Dinnebier, Dalton Trans., 2017, 46, 15216-15227.

10 D. C. Wallace, C. M. Brown and T. M. McQueen, J. Solid State Chem., 2015, 224, 28-35.

11 J. H. Roudebush, K. A. Ross and R. J. Cava, Dalton Trans., 2016, 45, 8783-8789.

12 T. R. Welberry and B. D. Butler, J. Appl. Crystallogr., 1994, 27, 205-231. 
13 K. Kitagawa, T. Takayama, Y. Matsumoto, A. Kato, R. Takano, Y. Kishimoto, S. Bette, R. Dinnebier, G. Jackeli and H. Takagi, Nature, 2018, 554, 341-345.

14 R. D. Shannon, Acta Crystallogr., Sect. A: Cryst. Phys., Diffr., Theor. Gen. Crystallogr., 1976, 32, 751-767.

15 A. Pabst, Am. Mineral., 1946, 31, 539-546.

16 R. D. Shannon, D. B. Rogers and C. T. Prewitt, Inorg. Chem., 1971, 10, 713-718.

17 B. U. Koehler and M. Jansen, Z. Anorg. Allg. Chem., 1986, 543, 73-80.

18 V. Todorova, A. Leineweber, L. Kienle, V. Duppel and M. Jansen, J. Solid State Chem., 2011, 184, 1112-1119.

19 K. Ramesha, A. S. Prakash, M. Sathiya, G. Madras and A. K. Shukla, J. Mater. Sci. Eng. B, 2011, 176, 141-146.

20 M. M. J. Treacy, J. M. Newsam and M. W. Deem, Proc. R. Soc. London, Ser. A, 1991, 433, 499-520.

21 P. W. Stephens, J. Appl. Crystallogr., 1999, 32, 281-289.

22 A. Leineweber, J. Appl. Crystallogr., 2006, 39, 509-518.

23 V. K. Medvedev, Y. Suchorski and J. H. Block, Ultramicroscopy, 1994, 53, 27-35.

24 P. A. Stadelmann, Ultramicroscopy, 1987, 21, 131-145.

25 P. J. Chupas, X. Qiu, J. C. Hanson, P. L. Lee, C. P. Grey and S. J. L. Billinge, J. Appl. Crystallogr., 2015, 36, 1342-1347.

26 G. Ashiotis, A. Deschildre, Z. Nawaz, J. P. Wright, D. Karkoulis, F. E. Picca and J. Kieffer, J. Appl. Crystallogr., 2015, 48, 510-519.

27 C. J. Wright and X. D. Zhou, J. Synchrotron Radiat., 2017, 24, 506-508.

28 TOPAS 6.0, Bruker AXS, 2017.

29 H. M. Rietveld, J. Appl. Crystallogr., 1969, 2, 65-71.

30 R. W. Cheary and A. Coelho, J. Appl. Crystallogr., 1992, 25, 109-121.
31 R. W. Cheary, A. A. Coelho and J. P. Cline, J. Res. Natl. Inst. Stand. Technol., 2004, 109, 1-25.

32 X. Qiu, J. W. Thompson and S. J. L. Billinge, J. Appl. Crystallogr., 2004, 37, 678-678.

33 T. Proffen and S. J. L. Billinge, J. Appl. Crystallogr., 1999, 32, 572-575.

34 C. L. Farrow, P. Juhas, J. W. Liu, D. Bryndin, E. S. Božin, J. Bloch, T. Proffen and S. J. L. Billinge, J. Phys.: Condens. Matter, 2007, 19, 335219.

35 B. E. Warren, Phys. Rev., 1941, 59, 693-698.

36 A. A. Coelho, J. Appl. Crystallogr., 2003, 36, 86-95.

37 G. S. Pawley, J. Appl. Crystallogr., 1981, 14, 357361.

38 X. Wang, J. Li, R. D. Hart, A. van Riessen and R. McDonald, J. Appl. Crystallogr., 2011, 44, 902-910.

39 S. Bette, R. E. Dinnebier and D. Freyer, J. Appl. Crystallogr., 2015, 48, 1706-1718.

40 C. M. Ainsworth, J. W. Lewis, C.-H. Wang, A. A. Coelho, H. E. Johnston, H. E. A. Brand and J. S. O. Evans, Chem. Mater., 2016, 28, 3184-3195.

41 S. Mangelsen, B. R. Srinivasan, U. Schürmann, L. Kienle, C. Näther and W. Bensch, Dalton Trans., 2019, 48, 11841201.

42 A. Kudielka, S. Bette, R. E. Dinnebier, M. Abeykoon, C. Pietzonka and B. Harbrecht, J. Mater. Chem. C, 2017, 5, 2899-2909.

43 A. A. Coelho, J. S. O. Evans and J. W. Lewis, J. Appl. Crystallogr., 2016, 49, 1740-1749.

44 R. E. Dinnebier, A. Leineweber and J. S. O. Evans, in Rietveld Refinement - practical powder diffraction pattern analysis using TOPAS, Walter de Gruyter, Berlin/Boston, 2019, ch. 12 Multiple Datasets, pp. 270-271. 